\title{
LA DIALÉCTICA ENTRE LA DEMOCRACIA REPRESENTATIVA Y PARTICIPATIVA EN EL ORDEN CONSTITUCIONAL DE LA UNIÓN EUROPEA
}

JOSU DE MIGUEL BÁRCENA 


\section{SUMARIO}

1. INTRODUCCIÓN. 2. LA DIALÉCTICA CONSTITUCIONAL ENTRE LA REPRESENTACIÓN POLÍTICA Y EL PRINCIPIO PARTICIPATIVO EN LA UNIÓN EUROPEA: TESIS DE PARTIDA. 3. LA GOBERNANZA LIBERAL: UNA APROXIMACIÓN TEÓRICA GENERAL. 4. LA EMERGENCIA CONSTITUCIONAL DE LA GOBERNANZA EN EL PROYECTO POLÍTICO EUROPEO: 4.1. La nueva gobernanza europea y el propium del estado de derecho. 4.2. La crisis de la teoría de la constitución económica europea y el método abierto de coordinación. 5. LA GOBERNANZA EUROPEA, EL MÉTODO ABIERTO DE COORDINACIÓN Y LA DEMOCRACIA PARTICIPATIVA COMO RESPUESTA. 6. EL RECONOCIMIENTO DEL PRINCIPIO DE DEMOCRACIA PARTICIPATIVA EN EL TRATADO CONSTITUCIONAL DE LA UNIÓN EUROPEA. 7. LA INCOMPATIBILIDAD MANIFIESTA ENTRE LA DEMOCRACIA PARTICIPATIVA Y REPRESENTATIVA COMO FORMAS DE LEGITIMACIÓN CONCURRENTES DEL PODER PÚBLICO EUROPEO. 8. CONCLUSIONES. 


\title{
LA DIALÉCTICA ENTRE LA DEMOCRACIA REPRESENTATIVA Y PARTICIPATIVA EN EL ORDEN CONSTITUCIONAL DE LA UNIÓN EUROPEA
}

POR

\author{
JOSU DE MIGUEL BÁRCENA \\ Becario de Investigación \\ Universidad del País Vasco
}

\section{INTRODUCCIÓN}

La Unión Europea parece embarcada en un extraño viaje, si se nos permite la alusión cinematográfica. Por un lado, resulta incuestionable que existe un consenso general entre la doctrina y la práctica política, para afirmar el agotamiento de los mecanismos iusinternacionalistas a la hora de legitimar y acercar a la ciudadanía el poder público comunitario. La emergencia de un constitucionalismo europeo, que en razón de su condición estructural y ordenadora del poder político, se ha ido formulando a través de conceptos y elementos proyectados desde las tradiciones constitucionales comunes de los Estados miembros, así lo atestiguaría 1 .

1 Díez Picazo, L. M.: Constitucionalismo de la Unión Europea, Civitas, Madrid, 2002; RodRíguez IgLESIAS, G. C.: "La constitucionalización de la Unión Europea", $R e-$ vista de Derecho Comunitario Europeo, n. ${ }^{\circ} 16,2003$, pp. 893-896, y CRUz VILLALón, P.: La Constitución inédita. Estudios ante la constitucionalización de Europa, Trotta, Madrid, 2004. 
Sin embargo, el constitucionalismo feliz en el que todos parecemos ocupados, cuyo exponente más claro es sin duda el por el momento inédito Tratado Constitucional de la Unión Europea, no puede hacernos perder de vista la realidad institucional comunitaria, no siempre reflejada en la letra de los Tratados, de la que devienen formas de intervención política hasta ahora no conocidas y en la que irrumpen novedosas dinámicas materiales enfocadas a neutralizar el viejo método comunitario de adopción de decisiones. A partir de estas premisas, el presente trabajo pretende aproximarse a las líneas generales del debate constitucional en torno a la gobernanza europea. Para ello, proponemos llamar la atención sobre las repercusiones que para el derecho y la democracia supranacional y estatal, tiene la institucionalización del Método Abierto de Coordinación, paradigma gubernamental de la política económica de la Unión Europea.

Como oposición teórica al gobierno clásico, la gobernanza plantea la reconversión de aquellos institutos convencionales que han servido para presentar la idea de la democracia, como un proceso que se realiza en el escenario de la historia ${ }^{2}$. Uno de los institutos a los que mayor tensión se somete en el contexto de este discurso, es sin lugar a dudas el principio de la representación política, cuya función legitimadora del poder constitucional es puesta en cuestión por las nuevas relaciones entre el Estado, la sociedad y el mercado, que surgen en los tiempos de la globalización. Así las cosas, la gobernanza liberal propone la recuperación de las tesis participativas y consensuales, con el objetivo de que los ciudadanos puedan hacer valer mejor sus intereses, satisfacer sus aspiraciones y, en última instancia, el poder político pueda recuperar las adhesiones y las lealtades perdidas por el camino del parlamentarismo discutidor ${ }^{3}$.

Como no podía ser de otra forma, la Unión Europea, que pasa por ser una forma política avanzada de gobernanza, no es ajena a este estado de cosas. Por un lado, el Método Abierto de Coordinación pretende suplir la ausencia de control democrático y jurídico de sus acuerdos políticos, a través de un enfoque institucional descentralizado que in-

2 Sobre esta terminología, ver VEGA GARCíA, P. de: «La democracia como proceso (consideraciones en torno al republicanismo de Maquiavelo)", Revista de Estudios Políticos, n. ${ }^{\circ}$ 120, 2003, pp. 8 y 9, y CABo MARTín, C. de: «El elemento utópico, ingrediente cultural del constitucionalismo", en BALAGUER CALLEJón, F. (coord.): Derecho Constitucional y Cultura. Estudios en homenaje a Peter Häberle, Tecnos, Madrid, 2004, pp. 47-55.

3 Nos parece interesante recuperar aquí la expresión de ScHMITT, C.: Sobre el parlamentarismo, Tecnos, Madrid, 1990, pp. 12-18. 


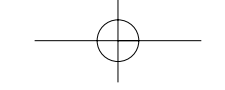

LA DIALÉCTICA ENTRE LA DEMOCRACIA REPRESENTATIVA Y PARTICIPATIVA...

tegre directamente las opiniones de los diferentes niveles gubernamentales y de los actores corporativos de la nueva sociedad civil trasnacional; por otro, el Tratado Constitucional reconoce en su art. I-47 la validez del principio de democracia participativa para articular la vida democrática de la Unión. Se trata entonces de explorar las relaciones teóricas entre la democracia representativa y participativa en el orden constitucional comunitario, a partir de la conexión que se establece entre la propuesta de la gobernanza liberal, la nueva Constitución económica europea y la experiencia institucional del Método Abierto de Coordinación.

\section{LA DIALÉCTICA CONSTITUCIONAL ENTRE LA REPRESENTACIÓN POLÍTICA Y EL PRINCIPIO PARTICIPATIVO EN LA UNIÓN EUROPEA: TESIS DE PARTIDA}

El art. I-46 del Tratado Constitucional (en adelante TC) señala de forma enfática que el "funcionamiento de la Unión se basa en la democracia representativa ${ }^{4}$. Se ha destacado, no sin cierta razón, que el principio representativo hace de esta forma entrada con fuerza en el ordenamiento jurídico comunitario, a través del complejo equilibrio entre lo que supone la legitimación directa del Parlamento Europeo (en adelante PE), que históricamente ha representado uno de los puntos de fuerza de las batallas federalistas, y la legitimación indirecta de la democracia mediada por los Estados y sus gobiernos dentro del Consejo de la Unión Europea 5 .

Sin embargo, a nuestro entender, el art. I-46 TC no aporta nada nuevo con respecto a la situación precedente trazada por los Tratados constitutivos. Supone, en realidad, lo que podríamos denominar como la síntesis teórica de los elementos idealistas y realistas de la "perspectiva europea de la representación ${ }^{6}$. Siguiendo con este argumento, el principio representativo asomaría en primer lugar como un almacén de conceptos destinado a recomponer una cierta unidad europea de ca-

4 La versión que utilizamos en todo el texto es el Tratado por el que se establece una Constitución para Europa, Ministerio de Asuntos Exteriores y de Cooperación, Ministerio del Interior y Ministerio de la Presidencia, Madrid, 2005.

5 CARTABIA, M.: "Inspirata alla volontà dei cittadini degli statu d’Europa», Quaderni Costituzionali, n. ${ }^{\circ} 1,2005$, pp. 9-37.

6 Parafraseando a HABERLE, P.: «Representación en la UE. Una contribución a la teoría constitucional europea", Fundamentos. Cuadernos monográficos de Teoría del Estado, Derecho Público e Historia Constitucional, n. 3, 2004. 
rácter social, política y de mercado, tal como lo hizo en la formación de la unidad nacional en los albores del Estado moderno. Resulta ilustrativo, a este respecto, el mandato valorativo, en el sentido de que su cometido está destinado a determinar el contenido material de la comunidad política europea, que el TC atribuye a los partidos políticos a escala comunitaria. El art. I-46.4 TC señala, en términos similares a como lo hace el art. 191 del Tratado de la Comunidad Europea (en adelante TCE), que "Los partidos políticos de dimensión europea contribuirán a formar la conciencia política europea y a expresar la voluntad de los ciudadanos». De igual manera, la Carta de Derechos Fundamentales incluida en el propio TC, en su art. II-72.2, reconoce que los partidos políticos a escala comunitaria "contribuyen a expresar la voluntad política de los ciudadanos de la Unión» 7.

En segundo lugar, inherente a su condición federal, sería el pragmatismo político que desde los albores de la integración europea ha caracterizado al sistema representativo de la Unión, pragmatismo que aún puede identificarse sin excesivas dificultades en el TC. El cuadro institucional comunitario, donde se mezclan aspectos federales, reguladores y parlamentarios, se ha presentado como una plataforma perfecta para llevar a cabo tres tareas sin las que no es posible entender la verdadera razón de ser de la Unión política y económica, con respecto a la forma estatal que la precede y la dota de fines: la búsqueda del equilibrio y la estabilidad política y constitucional tanto en el nivel comunitario como en el nacional, la difusión de una narrativa ideológica liberal caracterizada por la mesura democrática, y la reducción de la complejidad social y económica a través del compromiso funcional entre las partes constituyentes, los Estados miembros ${ }^{8}$.

Por lo demás, nos parece interesante añadir que a diferencia de los Tratados que le preceden, el TC asocia los derechos políticos de los ciudadanos comunitarios al principio de democracia representativa, aunque también es verdad que calla en lo que concierne a las relaciones entre aquellos y el principio de igualdad democrática. Ello resulta problemático en la medida en que se afirma que la democracia representativa europea fundamenta no sólo la existencia y elección por sufragio universal del PE, sino también la participación de los represen-

7 Resulta difícil encontrar una constitucionalización tan valorativa de los partidos políticos en el contexto constitucional de los Estados miembros, si quizá exceptuamos el art. 21 de la Ley Fundamental de Bonn, el art. 4 de la Constitución francesa, el art. 23 de la Constitución finlandesa o el art. 6 de la Constitución española.

8 Esta visión global del proyecto europeo sintetiza en realidad el pensamiento de Hallstein, W.: La Europa inacabada, Plaza \& Janés, Barcelona, 1971. 
tantes de los gobiernos nacionales en el proceso de toma de decisiones europeo. Como ha señalado la doctrina, la consideración de ambas realidades como dos caras de la misma moneda parece incorrecta, dado que el tipo e intensidad de la representatividad democrática es bien distinta en ambos casos, y dado que puede llevar a pensar que la debilidad institucional del PE se ve compensada por el papel asignado a los gobiernos nacionales en el Consejo'.

Por lo tanto, en nuestra opinión, el énfasis formalista del art. I-46.1 $\mathrm{TC}$, donde se reconoce que el "funcionamiento de la Unión se basa en la democracia representativa", quizá deba de ser interpretado teniendo en cuenta la referencia conceptual y teórica que proporciona el art. I-47 TC, donde se desarrollan los elementos fundamentales de la democracia participativa europea. En un principio, cabría pensar que el TC formula una estructura que deja sustancialmente abierta, y no resuelta, la cuestión del equilibrio entre dos concepciones de la democracia constitucional. Todo ello porque al igual que en las tradiciones constitucionales comunes ${ }^{10}$, las instancias de control y responsabilidad democráticas, que pertenecen a la herencia del constitucionalismo moderno, conviven necesariamente con instituciones de legitimación directa, legado de las experiencias constitucionales de las democracias del siglo $\mathrm{XX}^{11}$.

Esta imagen podría considerarse acertada en líneas generales, si nos atenemos a los argumentos y la metodología desarrollados por la ciencia política y constitucional en el contexto institucional del Estado. Sin embargo, deviene insuficiente como fórmula interpretativa de la transformación constitucional que está teniendo lugar en la Unión, más allá incluso de la innovación que supone el propio TC. Bajo nuestra perspectiva, la dialéctica que se establece en el Título VI del TC, entre la democracia representativa y participativa, únicamente puede comprenderse bajo el prisma de la reconversión del gobierno comunitario en gobernanza, la des-juridificación de la Constitución económica y la recreación de nuevas formas de intervención pública paralelas al método comunitario de gobierno, tal es el caso del Método Abierto de Coordinación.

9 MenÉnDEZ, A. J.: "Esperando a la Constitución Europea», Revista Española de Derecho Constitucional, n. ${ }^{\circ}$ 72, 2004, p. 101.

10 HÄBERLE, P.: "Derecho Constitucional común europeo», Revista de Estudios Políticos, n. ${ }^{\circ} 79,1993$.

${ }_{11}$ Pensemos en el caso de la iniciativa legislativa popular, recogida a su vez en el art. I-47.4 TC; sobre esta cuestión, ver RIDOLA, P.: "La parlamentarización de las estructuras institucionales de la Unión Europea entre democracia representativa y democracia participativa", Revista de Derecho Constitucional Europeo, n. ${ }^{\circ}$ 3, 2005. 
Y es que el espacio político europeo trata de expandirse, a marchas forzadas, a través de la propuesta teórica constitucional formulada por la gobernanza liberal. Los problemas de legitimidad y eficacia que acusa el proceso de integración europea y el agotamiento de la teoría de la Constitución económica tal como había sido entendido hasta el Tratado de Maastricht, conducen cada vez más a la configuración de formas democráticas experimentales, que sirvan tanto para acortar la creciente distancia que parece instaurarse entre los gobernantes y los gobernados, como para establecer un modelo de relación entre la política y la economía que permita mantener el vínculo social que ha caracterizado al Estado del bienestar continental ${ }^{12}$. En torno a estas circunstancias, aparecen las nociones de democracia participativa y de sociedad civil europea, el nuevo método y el nuevo sujeto destinados a fomentar la ficción de que la ley comunitaria es en realidad fruto de la voluntad de los ciudadanos europeos ${ }^{13}$. A continuación, trataremos de sintetizar de manera general cuáles son las características de la nueva gobernanza liberal, y cómo se concretan en el orden constitucional europeo.

\section{LA GOBERNANZA LIBERAL: UNA APROXIMACIÓN TEÓRICA GENERAL}

La gobernanza liberal es un concepto de moda dentro de la ciencia política y constitucional contemporánea. Su aparición se debe en parte a la necesidad de buscar respuestas teóricas a la crisis de gobernabilidad, que por el contrario hace referencia a un estado de cosas concreto en el conjunto de las democracias occidentales: las expectativas sociales de los ciudadanos y sus demandas al Estado han aumentado considerablemente y los recursos de éste para satisfacerlas han disminuido, lo que genera un importante grado de frustración y rechazo ${ }^{14}$.

12 Sobre estas cuestiones, recomendamos ver WALLACE, W., y SMITH, J.: «Democracy or Technocracy? European Integration and the Problem of Popular Consent", en HAYWARD, J. (ed.): The Crisis of Representation in Europe, Frank Cass, Londres, 1995, y WeILER, J. H. H.: «Does Europe Need a Constitution? Demos, Telos and the German Maastricht Decision», European Law Journal, VI. 1, n. ${ }^{\circ}$ 3, 1995.

13 WILKINSON, M. A.: "Civil Society and the Re-imagination of European Constitutionalism", European Law Journal, VI, 9, n. ${ }^{\circ}$ 4, 2003, pp. 451-472.

14 Alcántara, S. M.: Gobernabilidad, crisis y cambio. Elementos para el estudio de la gobernabilidad de los sistemas políticos en épocas de crisis y cambio, Fondo de Cultura Económica, México, 1995, y VALADÉs, D., y GutiÉRREZ Rivas, R. (eds.): Democracia y gobernabilidad. Memoria del IV Congreso Nacional de Derecho Constitucional II, Universidad Nacional Autónoma de México, México, 2001. 
Las condiciones políticas y económicas que impone el régimen de la globalización, modifican los pilares sobre los que asentaba la acción gubernamental del Estado social: fin de la estabilidad del sistema financiero, crisis energética, abandono del sistema Breton Woods, generalización de los intercambios financieros y comerciales y ruptura del consenso social básico ${ }^{15}$. En este contexto, la gobernanza liberal preconiza una redefinición del gobierno tradicional, en un sentido horizontal, donde las funciones del Estado tienen que hacerse compatibles con el nuevo escenario económico y político global. Este escenario, de carácter provisional, requiere una intervención política guiada por los principios de eficacia, flexibilidad y especialización ${ }^{16}$.

La gobernanza recupera una vieja idea liberal que había sido desechada tras la crisis del periodo de entreguerras: el mercado es una instancia de ordenación no sólo económica, sino también social. Esto no viene a significar, ni mucho menos, que el poder político estatal desaparezca de la escena, únicamente que modifica sus tareas convencionales, enfocándolas hacia la creación de simulacros de equilibrio y seguridad a través de una maquinaria estatal escasa pero a la vez efectiva y funcional ${ }^{17}$. En las nuevas relaciones entre el Estado, la sociedad y el mercado, la acción gubernamental clásica, caracterizada por su verticalidad institucional, debe de transformarse en una gobernanza de tipo horizontal, que intente involucrar a todos aquellos intereses de los actores sociales, administrativos y empresariales, que dirigen y gestionan la sociedad y la economía. La función clave no es tanto la redistribución de recursos, como la regulación del riesgo social y político, lo que implica la formalización de un proceso decisorio dirigido a la solución de problemas y que debe de tener en cuenta la simbiosis entre los poderes públicos y los privados ${ }^{18}$.

Por esta razón, la gobernanza liberal propone la institucionalización de nuevos espacios, métodos y protagonistas para la acción política, procurando que cada individuo sea multipartícipe y conecte de forma esporádica con los diferentes nudos intercomunicativos que

15 García Herrera, M. A.: «Estado, Comunidades Autónomas y Derechos Sociales: Relaciones y Tendencias", El Estado Autonómico: cooperación y conflicto, Anuario Jurídico de la Rioja, n. ${ }^{\circ}$ 8, 2002, p. 109.

16 RHODES, R.: "The New Governance: Governing Without Government», Political Studies, VI, 44, n. ${ }^{\circ} 4,1996$, pp. 652-653.

17 Negri, T., y HARDT, M.: El trabajo de Dionisos, Akal, Madrid, 2003, p. 58.

18 Koolman, J.: "Social - political governance: introduction», en KooımaN, J. (ed.): Modern governance: New government - society interactions, Sage, Londres, 1993, p. 2. 
caracterizan a la estructura de la sociedad red capitalista ${ }^{19}$. Mientras la superestructura digital permite una forma de democracia continua, "donde la voz de los ciudadanos se puede alzar en cualquier momento y desde cualquier lugar y formar parte del concierto económico [y político] cotidiano", la sustitución del pueblo como sujeto político representado, por una plétora de asociaciones y corporaciones en la frontera entre lo público y lo privado, facilita la adecuación del viejo gobierno a la nueva sociedad y economía descentrada y funcionalmente diferenciada ${ }^{20}$.

\section{LA EMERGENCIA CONSTITUCIONAL DE LA GOBERNANZA EN EL PROYECTO POLÍTICO EUROPEO}

La nueva gobernanza europea está entre nosotros desde hace bastante tiempo. Lamentablemente, al no encontrarse institucionalizada en los Tratados comunitarios, ha pasado desapercibida para la mayor parte de los juristas y politólogos. La gobernanza europea no es, como muchos han tratado de ver, un conjunto de reglas, procesos y comportamientos que afectan a la forma en que los poderes de la Unión son ejercidos ${ }^{21}$. Por el contrario, la gobernanza europea puede ser entendida como la desconstrucción del método comunitario de gobierno clásico, a través de novedosas formas de elaboración, ejecución y control de las políticas públicas, que se inscriben en lo que de un tiempo a esta parte se ha venido a denominar desde el derecho constitucional y administrativo, como experimentalismo democrático ${ }^{22}$.

En la Unión Europea, la gobernanza liberal ha tomado el nombre de Método Abierto de Coordinación (en adelante MAC). EI MAC es el sistema de gobierno de la política económica comunitaria, un tipo de gobierno débil no constitucionalizado, que llega avalado por su hipotética capacidad para combinar la coherencia con el respeto a la diversidad

19 CABo Martín, C. de: "Transformaciones actuales del Estado y del Derecho: Perspectivas Teóricas", en García Herrera, M. A.: El constitucionalismo en la crisis del Estado social, Universidad del País Vasco, Bilbao, 1997, p. 560.

20 BOYER, W. W.: "Political Science and the 21st Century: From Government to Governance», Political Science \& Politics, VI, 28, n. ${ }^{\circ} 1,1990$, p. 51.

21 Quizá el ejemplo más claro de esta definición se corresponda con la visión de la Comisión de las Comunidades Europeas, La Gobernanza Europea. Un libro blanco, COM (2001) 428 final, Bruselas, 25.7.2001.

22 Por todos, ver en este sentido DORF, M. C., y SABEL, C. F.: "A Constitution of Democratic Experimentalism», Columbia Law Review, VI, 98, n. ${ }^{\circ} 2$, 1998, pp. 267473. 


\subsection{La nueva gobernanza europea y el propium del Estado de derecho}

Los antecedentes teóricos que invocan los defensores del MAC han sido desarrollados al margen del marco europeo. Han sido experimentados en el derecho administrativo americano antes de ser presentados en Europa y de que se fusionasen con el $\mathrm{MAC}^{27}$. El enfoque propuesto por el experimentalismo democrático antes mencionado, se inspira en la esfera social, principalmente de las prácticas organizativas de las empresas, prometiendo una institucionalización exitosa de los principios de evaluación comparada, ingeniería simultánea y control independiente que permite manejar mejor la volatilidad y la diversidad económica.

Sin embargo, esta preciosa música tiene sus defectos en la letra, principalmente los derivados de lo que paradójicamente puede designarse como creciente des-normativización del derecho comunitario. EI MAC se basa, fundamentalmente, en el despliegue de un decisionmaking flexible, cuyo centro de poder se sitúa en el todopoderoso Consejo Europeo, donde progresivamente se pasa de un sistema basado en reglas y procedimientos sujetos a la observancia de un intérprete independiente, como en realidad ocurre en el método comunitario, a un sistema basado en la mera decisión política de los Estados miembros ${ }^{28}$. Supone, por decirlo más claramente, la marginalización de la Comisión Europea, el PE y el Tribunal de Justicia de las Comunidades Europeas (En adelante TJCE), del proceso político comunitario. La crisis política y el desenlace jurídico del Pacto de Estabilidad, considerado el auténtico paradigma del MAC, no hacen sino reforzar esta idea $^{29}$.

Este nuevo modo de gobernanza, conduce a la producción de un tipo de derecho tan poco vinculante, que en ocasiones ha llevado a más de un jurista a preguntarse si puede ser caracterizado como au-

27 El ejemplo más claro al respecto, en ScotT, J., y T6, D. M.: “Mind the Gap: Law and New Approaches to Governance in the European Union", European Law Journal, VI, 8, n. ${ }^{\circ}$ 1, 2002, pp. 1-18.

28 Closa Montero, C.: "Lecciones del Pacto de Estabilidad", Real Instituto Elcano de Estudios Internacionales y Estratégicos, Papel de análisis n. ${ }^{\circ} 22 / 2004$, http://www.realinstitutoelcano.org/.

29 Sobre esta cuestión, recomendamos ver QUADRA - SALCEDO JANINI, T. de la: "La discrecionalidad política del ECOFIN en la aplicación del procedimiento por déficit excesivo. Reflexiones tras la Sentencia del TJCE del 13 de Julio de 2004", Revista de Estudios Políticos, n. ${ }^{\circ} 126,2004$, pp. 151-176. 


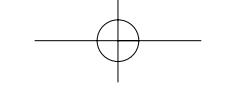

téntico derecho ${ }^{30}$. Como se sabe, el proceso político en el Consejo Europeo y en el ECOFIN está marcado por dos características: primero, es informal en cuanto que simplemente se basa en la reunión de información, el esbozo de planes de acción, la adjudicación de elogios públicos por las mejores prácticas y la puesta en evidencia de los Estados que no hayan alcanzado los objetivos mínimos; segundo, aún cuando las nuevas formas de gobernanza han sido designados por áreas políticas limitadas, son sin embargo holísticas, lo que significa que implican la actuación en conjunto de los gobiernos, así como un amplio número de interesados ${ }^{31}$. En consecuencia, estamos ante un poder no vinculante y difuso, que está ejerciendo su dominio sin ser constreñido por las normas que gobiernan la atribución de competencias, la responsabilidad democrática y su control judicial tanto a nivel estatal como supranacional.

Por lo tanto, en cuanto a la gobernanza y sus relaciones con el derecho, podemos acabar concluyendo que el experimentalismo democrático que lo caracteriza, nos invita, cuando menos, a tomar a la ligera las virtudes del Estado de derecho. Todo ello sin tener en cuenta que la Unión ha tomado históricamente la vía de la legitimación a través del derecho, y que en los Estados miembros acontece una inesperada revalorización de la ley frente a la Constitución ${ }^{32}$. Pero cuando se nos invita a que aflojemos los lazos existentes entre el derecho y la imposición de su cumplimiento, hemos de saber que se traslada la naturaleza jurídico-política de la Unión desde lo constitucional a lo internacional, y lo que es aún peor, se termina por difundir la idea de que nuestras sociedades pueden administrarse con escasos poderes de intervención gubernamental ${ }^{33}$.

30 Everson, M.: "The Constitutional Law of the Euro? Disciplining European Governance", en BEAUMONT, P, y WALKER, N. (eds.): Legal framework of the Single European Currency, Oxford University Press, Oxford, 1999, p. 120.

31 BorRÁs, S., y JACOBSSON, K.: "The open method of co-ordination and new governance patterns in the EU», Journal of European Public Policy, 11: 2, 2004, pp. 185-208.

32 Zagrebelsky, G.: «La Ley, el Derecho y la Constitución», Revista Española de Derecho Constitucional, n. ${ }^{\circ} 72,2004$, pp. 11-24.

33 Un ejemplo de lo afirmado en ScotT, J.: "International Trade and Environmental Governance: Relating Rules (and Standards) in the EU and the WTO», European Journal of International Law, n. 15,2004 , pp. 307 y ss. 


\subsection{La crisis de la teoría de la Constitución económica europea y el Método Abierto de Coordinación}

Hasta el Tratado de Maastricht, la Unión se constituyó como una comunidad política dual en lo referente a lo económico y lo social ${ }^{34}$. Los Tratados comunitarios perfilaban una constitución económica apolítica y neutral en el sentido de que no estaba sujeta a intervenciones políticas. Ésta era su raison d'être constitucional y supranacional. Sin embargo, la política social era tratada como una materia categóricamente distinta, constituía un dominio de la legislación política y, por tanto, debía permanecer en el ámbito nacional. Así pues, el enraizamiento del mercado en la sociedad podía y debía ser llevado a cabo por los Estados miembros de manera diferenciada.

El Acta Única Europea supuso, en este sentido, el comienzo de las invasiones del mercado a las políticas sociales de los Estados miembros. La iniciativa de la Comisión Delors acerca del mercado interior ha sido interpretada, con el transcurrir del tiempo, como un esfuerzo por consolidar y dar prioridad a la institucionalización de la racionalización económica en el proyecto de integración europea. El reforzamiento de las libertades económicas fomentó los procesos de competencia entre regulaciones, y expuso a la legislación nacional a controles reiterados desde el marco supranacional. La Unión Monetaria, el pacto de Estabilidad y la Agenda de Lisboa, no son sino la culminación de un largo proceso por limitar la apariencia ordoliberal de la Constitución económica europea, y por mostrar una voluntad decidida por parte de los Estados miembros, en acrecentar el control político sobre la economía capitalista europea ${ }^{35}$. Sin embargo, con esta tendencia, se rompía el dualismo histórico entre la política de mercado comunitaria y la política económica de los Estados miembros.

El fracaso del Pacto de Estabilidad y de la Agenda de Lisboa, indica que los Estados no han sido sin embargo capaces de cumplir con un compromiso constitucional que nació de la necesidad de encontrar una respuesta supranacional no política en un ámbito político y económico, la política fiscal y presupuestaria, que es parte esencial de la

34 JoERges, C.: “¿Qué tiene de social-demócrata la constitución económica europea?", Revista Española de Derecho Constitucional, n. ${ }^{\circ} 73,2005$, pp. 9-53.

35 Sobre el carácter ordoliberal de la Constitución económica europea, recomendamos ver MAestro Buelga, G.: "Constitución económica e integración europea", Revista de Derecho Político, n. ${ }^{\circ}$ 54, 2002, pp. 33-111, y SchARPF, F .W.: Gobernar Europa, ¿Eficaz y democráticamente?, Alianza, Madrid, 2000. 
soberanía popular y de la política sujeta a control parlamentario ${ }^{36}$. Más allá del debate en torno a la eficiencia, nos interesa explicar a continuación cómo el carácter monista de la nueva Constitución económica europea, ha tenido efectos devastadores en las democracias de los Estados miembros, en parte gracias a la ayuda inestimable de la gobernanza y su renovado soporte institucional, el MAC. La razón para ello no resulta difícil de comprender.

Efectivamente, los instrumentos de intervención política comunitaria en la economía, esto es, Unión Monetaria, convergencia presupuestaria y grandes orientaciones de política fiscal, se consagran como una fórmula macroeconómica frágil, pero que actúan como mecanismo efectivo de disciplina económica global entre el Estado y la Unión ${ }^{37}$. Se crea así un doble espacio virtual de dirección económica y política: formalmente, la política económica se mantiene en manos de los Estados miembros; materialmente, las directrices políticas europeas elaboradas a través del MAC, ejercen una influencia limitadora en la capacidad de los parlamentos nacionales y regionales para llevar a cabo políticas legislativas diferenciadas, lo que irremediablemente termina por provocar una desvalorización material de las Constituciones de los Estados miembros y una relativización de la idea de Poder Constituyente ${ }^{38}$.

Sin embargo, es en el contexto de la rendición de cuentas democráticas, donde el MAC despliega con mayor fuerza su capacidad para desvirtuar los atributos del gobierno constitucional ${ }^{39}$. Todo ello porque la absorción material de competencias gubernamentales de carácter económico por parte de la Unión, no se ve compensada con una democratización del ejercicio de esas competencias en el ámbito

36 JoERGES, C.: “¿Qué tiene de social-demócrata la constitución económica europea?", op. cit., p. 33.

37 Maestro Buelga, G.: «Poder constituyente, principio democrático y continuidad en el Tratado Constitucional de la Unión Europea», Teoría y Realidad Constitucional, n. ${ }^{\circ} 15,2004$, p. 154.

38 Al respecto, ver López PinA, A., y GutiérRez GutiérReZ, I.: «Preservación de la Constitución, reforma de los Tratados", en Civitas Europa, n. ${ }^{\circ}$ 7, 2001, p. 74; TAJADURA TEJADA, J.: "La crisis de la Constitución en el proceso de integración europea», en Revista de Derecho Político, n. ${ }^{\circ} 53,2002$, pp. 260-269, y LóPEZ CASTILLO, A.: "La Unión Europea "en constitución" y la Constitución estatal en (espera de) reformas. A propósito de la DTC 1/2004, de 13 de diciembre», en VV.AA.: Constitución Española y Constitución Europea, Centro de Estudios Políticos y Constitucionales, Madrid, 2005, p. 28.

39 OfFE, C.: «The European model of «social» capitalism. Can it survive European integration?", Journal of Political Philosophy, n. ${ }^{\circ} 11,2003$, pp. 437 y ss. 
supranacional. La ausencia de disposiciones vinculantes, el reforzamiento de los poderes ejecutivos y la marginalización del PE, la Comisión y del TJCE del proceso político, supone un paso más en la institucionalización de lo que algún comentarista ha denominado como la irresponsabilidad política organizada: la posibilidad de que los niveles de gobierno europeo, nacional y regional, terminen por culparse mutuamente de su incapacidad para resolver los problemas de unos ciudadanos, que atónitos, son incapaces de identificar quien adopta (o no adopta) finalmente las decisiones que realmente les concierne en materia social y económica ${ }^{40}$.

\section{LA GOBERNANZA EUROPEA, EL MÉTODO ABIERTO DE COORDINACIÓN Y LA DEMOCRACIA PARTICIPATIVA COMO RESPUESTA}

En el apartado segundo de este trabajo, señalábamos que la dialéctica constitucional entre el principio representativo y el principio participativo que prefigura el Título VI del TC, no podía entenderse como la oposición entre dos modelos de concebir la democracia constitucional, al menos tal y como lo hemos hecho hasta ahora: por un lado la democracia directa ejercida de forma inmediata por los propios ciudadanos, y por otro la democracia mediada a través de los partidos políticos y las instituciones. No resulta preciso, por lo demás, entrar a discernir los elementos fundamentales del debate teórico y político aludido $^{41}$. Lo que nos interesa resaltar a continuación, por el contrario, son las conexiones entre el principio participativo, tal y como se estructura en el TC, la gobernanza europea y el MAC.

El desarrollo de la hipótesis de la democracia participativa europea y su convergencia con la nueva gobernanza que propone el MAC, ha tenido diferentes momentos y sedes institucionales, pues en principio se trata de una idea lanzada por los Estados miembros y los órganos constitucionales de la Unión. Aparentemente, el Consejo Europeo de

40 El ejemplo alemán de irresponsabilidad política organizada puede comprobarse en el magnífico trabajo, de carácter divulgativo, del liberal DARNSTÄDT, T.: $L a$ trampa del consenso, Trotta, Madrid, 2005.

41 Las líneas generales de dicho debate, en BöcKENFÖRDE, E. W.: «Democracia y representación. Crítica a la discusión actual sobre la representación», en el VI. Estudios sobre el Estado de Derecho y la democracia, Trotta, Madrid, 2003, y SCHNEIDER, H. P.: "Soberano sin poder. Representación y participación del pueblo como problema de legitimación de la soberanía democrática», en el volumen del mismo autor Democracia y Constitución, Centro de Estudios Constitucionales, Madrid, 1991. 
Lisboa, de marzo de 2000, supone el momento fundacional del MAC y por extensión de la idea de democracia participativa comunitaria, al afirmar que una de las principales características del nuevo paradigma gubernamental que propugna es su "enfoque completamente descentralizado", que puede ser aplicado "de acuerdo con el principio de subsidiariedad [...]. La Unión, los Estados miembros, los niveles regionales y locales, así como los interlocutores sociales y la sociedad civil pueden y deben estar activamente implicados, empleando para ello distintas formas de relacionarse ${ }^{42}$.

Sin embargo, es importante hacer notar que la orientación plenamente corporativa y asociativa con el que el Consejo Europeo de Lisboa pretende dotar a la dimensión participativa del MAC, ya había sido constitucionalmente apadrinada por el TJCE con anterioridad. En su Sentencia T-135/96, de 17.6.1998, el Tribunal de Primera Instancia había afirmado, que a falta de intervención del PE en el proceso de adopción de un acto legislativo comunitario, algo palmario en el caso del MAC, «el principio de democracia, en el que se basa la Unión, requiere [...] que la participación de los pueblos en dicho proceso se garantice de forma alternativa (la cursiva es nuestra), en este caso a través de los interlocutores sociales que celebran el Acuerdo al que el Consejo, decidiendo por mayoría cualificada, a propuesta de la Comisión, confiere un soporte legislativo a escala comunitaria. Para controlar el cumplimiento de dicha exigencia, incumbe a la Comisión y al Consejo comprobar la representatividad (acumulada) de los interlocutores sociales interesados ${ }^{43}$.

La democracia participativa aparece entonces como el eslogan adecuado para suplir las carencias democráticas y jurídicas inherentes a la política económica de la Unión y a su soporte institucional, el MAC, carencias que vienen reforzadas por una metodología funcional y de trabajo dominada por el Consejo Europeo, el ECOFIN y la Comisión Europea $^{44}$. Si la instancia democrática comunitaria por antonomasia, el PE, se encuentra al margen del proceso político, la mejor solución parece

42 El texto completo puede comprobarse en las Conclusiones de la Presidencia, Consejo Europeo de Lisboa, 23 y 24 de marzo de 2000, http://europa.eu.int/council/off/conclu/mar2000/index.htm

43 Sentencia de 17.6.1998, Tribunal de Primera Instancia, Union Européenne de l'artisanant et des petites et moyennes entreprises vs. Consejo de la UE, T135/96, Recopilación de Jurisprudencia 1998, página II-02335, fundamento jurídico n. ${ }^{\circ} 89$.

${ }^{44}$ COUNCIL OF EUROPEAN UNION: "The on-going experience of the open method of coordination", Presidency Note, n. ${ }^{\circ}$ 9088/00, 13.6.2000. 
entonces implicar en la negociación institucional a todos aquellos actores de la sociedad civil que van a verse afectados por la ley, a través de una aplicación efectiva del principio de transparencia ${ }^{45}$. Como si el Pacto de Estabilidad, las políticas de empleo o la reforma de las pensiones afectasen únicamente a ciertos sectores y no a la sociedad europea en su conjunto.

El Libro Blanco de la Gobernanza Europea, elaborado por la Comisión Europea en 2001, como aportación al debate constitucional comunitario en ciernes, resultó clave a la hora de precisar aún más el contenido de la democracia participativa europea ${ }^{46}$. Como se sabe, uno de los puntos centrales del Libro Blanco de la Gobernanza Europea, era conseguir «que más personas y organizaciones se involucren en el diseño y formulación de las políticas comunitarias, a través del principio participativo $"{ }^{47}$. La Comisión creía conveniente la creación de una serie de canales complementarios a la representación política clásica, inserta en el método comunitario de gobierno, con la intención de implicar a la sociedad civil europea en alguno de los estadios de la formación de la voluntad comunitaria. Este diálogo comunicativo entre la administración y ciudadanos, terminaría por aportar una mayor legitimidad factual a la construcción política europea en su conjunto ${ }^{48}$.

Lo interesante $-y$ lo peligroso- del Libro Blanco de la Comisión, es que traslada las posibilidades de la democracia participativa desde el MAC hacia la forma constitucional comunitaria en su conjunto. Para ello, propone una transformación global de los protagonistas y el medio deliberativo para la acción política en el contexto de la nueva gobernanza. En cuanto a los sujetos, el ciudadano y el pueblo desaparecen de la escena y dejan paso a lo que sin apenas reparos conceptuales se denomina como sociedad civil europea, integrada por "partes interesadas", grupos de presión o "colectividades regionales", portadores todos ellos de una diversidad de intereses en plena

45 Schutter, O. de: "Europe in Search of its Civil Society», European Law Journal, VI, 8, n. ${ }^{\circ}$ 2, 2002, pp. 201-206, y TELÒ, M.: "Governance and government in the European Union. The open method of co-ordination», en RodRIGUES, M. J. (ed.): The New Knowledge Economy in Europe - A Strategy for International Competitiveness and Social Cohesion, Edward Elgar Publishing, Cheltenham, 2002, p. 265.

46 Comisión de las Comunidades Europeas, La Gobernanza Europea. Un libro blanco, COM (2001) 428 final, Bruselas, 25.7.2001.

47 Comisión de las Comunidades Europeas, La Gobernanza Europea. Un libro blanco, op. cit., pp. 12 y ss.

48 Comisión de las Comunidades Europeas, La Gobernanza Europea. Un libro blanco, op. cit., p. 16. 
competencia ${ }^{49}$. Por otro lado, los partidos políticos y el Parlamento, órganos representativos de la sociedad por antonomasia, se ven mediatizados por lo que se denomina como la elaboración interactiva de políticas, mecanismo digital de información de retorno que aspira a recoger las reacciones espontáneas de la celebrada sociedad civil europea, utilizando redes y puntos de contacto existentes como intermediarios, a fin de obtener un acceso continuo a las opiniones y experiencias de los operadores económicos comunitarios ${ }^{50}$.

\section{EL RECONOCIMIENTO DEL PRINCIPIO DE DEMOCRACIA PARTICIPATIVA EN EL TRATADO CONSTITUCIONAL DE LA UNIÓN EUROPEA}

Si echamos un vistazo al art. I-47 TC, podremos comprobar sin excesivas dificultades que la aprehensión jurídico - política que realiza del concepto de democracia participativa, es plenamente receptora del sistema de ideas que al respecto habían elaborado con anterioridad las diferentes instituciones comunitarias y los Estados miembros, al albor de la nueva gobernanza europea y de su expresión institucional más acabada, el MAC.

El principio participativo aparece en el art. I-47 TC como la concreción constitucional de un tipo de democracia plenamente corporativa y asociativa. En este contexto, la iniciativa legislativa popular que se recoge en el apartado cuarto del artículo mencionado, resulta anecdótica cuando no irrelevante ${ }^{51}$. Ello porque el principio participativo no es

49 Comunicación de la Comisión de las Comunidades Europeas, Documento de consulta: Hacia una cultura reforzada de consulta y diálogo. Propuesta de principios generales y normas mínimas para la consulta de la Comisión a las partes interesadas, COM (2002) 277 final, Bruselas, 5.6.2002, p. 3, y Comunicación de la Comisión de las Comunidades Europeas, Diálogo con las asociaciones de colectividades territoriales sobre la elaboración de las políticas de la Unión Europea, COM (2003) 811 final, Bruselas, 19.12.2003.

50 Comunicación de la Comisión de las Comunidades Europeas, sobre La elaboración interactiva de las políticas, COM (2001) 1014 final, Bruselas, 3.4.2001.

51 El apelativo de anecdótico resulta adecuado si tenemos en cuenta que el instituto de la iniciativa legislativa popular languidece en la mayor parte de los Estados miembros de la Unión. Por lo demás, en el art. l-47.4 se señala que al menos un millón de ciudadanos podrán tomar la iniciativa de invitar a la Comisión, en el marco de sus atribuciones, a que presente una propuesta adecuada sobre cuestiones que aquellos estimen que requiere un acto jurídico de la Unión. En este sentido, sorprende que se ponga en conexión a los ciudadanos y a la Comisión, un órgano al fin y al cabo regulador sin legitimidad democrática, y no a los ciudadanos y a las instituciones legislativas democráticas centrales de la Unión, el Consejo y el PE. 
configurado como un fin en sí mismo, en conexión permanente con la autodeterminación democrática, como es lo propio en el Estado constitucional ${ }^{52}$, sino como un instrumento al servicio de la mayor eficacia del gobierno de la Unión. Los ciudadanos aparecen como sujetos mediados a través de asociaciones y corporaciones, en una construcción jurídica e institucional donde la política únicamente retiene una función escolástica destinada a defender los intereses creados, construcción que desde luego recuerda, y mucho, a las tesis pluralistas de las primeras décadas del siglo pasado, concebidas como oposición teórica a la idea de soberanía política ${ }^{53}$.

En sus diferentes apartados, el art. I-47 TC señala como sujetos de la democracia participativa europea, a las "asociaciones representativas" (art. I-47.1 y 2), la sociedad civil (art. I-47.2) y las partes interesadas (art. 1-47.3), que tendrán la posibilidad de expresar e intercambiar públicamente sus opiniones en todos los ámbitos de actuación de la Unión, a través de un diálogo abierto, transparente y regular con las instituciones europeas.

A partir de este momento, se trata de verificar, sin más preámbulos, en qué medida el art. I-47 TC, consagra o no un tipo de democracia diferente, contrapuesta y al fin y al cabo negadora de la democracia representativa, tal y como hasta ahora se ha venido entendiendo en el Estado constitucional contemporáneo y como lo entiende el art. I-46 del propio TC.

\section{LA INCOMPATIBILIDAD MANIFIESTA ENTRE LA DEMOCRACIA PARTICIPATIVA Y REPRESENTATIVA COMO FORMAS DE LEGITIMACIÓN CONCURRENTES DEL PODER PÚBLICO EUROPEO}

En su Informe sobre el Libro Blanco de la Comisión y la Gobernanza Europea, el PE, a través de su Comisión de Asuntos Constitucionales, realizó una llamativa advertencia en torno al valor político de uno de los cinco principios de la buena gobernanza europea, el participativo. Para

52 Sobre esta cuestión, ver HABERMAS, J.: "Concepto de participación política», en ABENDROTH, W., y otros: Capital monopolista y sociedad autoritaria. La involución autoritaria de la República Federal Alemana, Fontanella, Barcelona, 1973, pp. 16-61.

53 La desintegración del principio democrático, en NiCHOLLS, D. G.: "La paradoja del Estado pluralista", en Cuadernos Constitucionales de la Cátedra Fadrique Furió Ceriol, n. ${ }^{0} 13,1995$, p. 52, y en la base de estas ideas, ver LASKI, H.: La gramática de la política. El Estado moderno, Comares, Granada, 2002, pp. 31-76. 
el PE, tal como se desplegaba en el Libro Blanco, el principio participativo únicamente podría servir para erosionar la ya de por sí frágil estructura parlamentaria comunitaria, al hacer menos transparente la toma de decisiones y al conferir legitimidad democrática a entidades autónomas y sectoriales, como es el caso de la sociedad civil organizada, incapaces por sí solas de asumir el interés general comunitario $^{54}$. Con esta declaración, el PE asume en solitario la idea de que el principio representativo está destinado a ejercer la misma función política y constitucional en el espacio estatal, que en el espacio supranacional.

En lo que respecta al ámbito del Estado constitucional, el parlamento y la representación política han tenido y tienen una función legitimadora ${ }^{55}$. En primer lugar, porque en la medida en que suponen la expresión teórica de los valores e intereses en que se plasma la unidad de la nación o del pueblo, se encuentran en un lugar inmejorable para conformar la voluntad general que trascienda y vertebre los intereses particulares contenidos en la comunidad política, en un sentido universalista ${ }^{56}$. En segundo lugar, porque al lograr concatenar la autodeterminación democrática, los derechos políticos y la participación ciudadana, la representación asegura la autonomía del proceso político respecto a otros aspectos que se desarrollan dentro del sistema social, autonomía que resulta fundamental para la legitimación mediante el procedimiento y la consiguiente reducción de la complejidad social ${ }^{57}$.

Seguramente está lejos el día en que el principio representativo pueda ejercer una función legitimadora tal como la que acabamos de describir, en el contexto de la Unión Europea. Los derechos políticos

54 Puntos 8, 9, 10, 11 y 12 del Informe del PE sobre el Libro Blanco de la Comisión, "La Gobernanza europea», A5-0399/2001, 15.11.2001, pp. 9 y 10.

55 La racionalidad literaria nos impide detenernos en exceso en una cuestión tan determinante. Recomendamos en cualquier caso, ojear los excelentes trabajos que el profesor Pedro de Vega García realizó sobre esta cuestión, teniendo en cuenta los problemas contemporáneos, al final de la década de 1990; VEGA GARCíA, P. de: "La función legitimadora del parlamento», en PAU VALL, F. (coord.): Parlamento y opinión pública, Tecnos, Madrid, 1995, pp. 229-240, y VEGA GARcíA, P. de: "Democracia, representación y partidos políticos (Consideraciones en torno al problema de la legitimidad)", en ASENSI, J. (coord.): Ciudadanos e instituciones en el constitucionalismo actual, Tirant lo Blanch, Valencia, 1997, en especial pp. 35-39.

56 SchmitT, C.: Teoría de la Constitución, Alianza Editorial, Madrid, p. 209 y KRIELE, M.: Introducción a la Teoría del Estado. Fundamentos históricos de la legitimidad del Estado constitucional democrático, Desalma, Buenos Aires, 1980, pp. 338 y ss.

57 KeLSEN, H.: Esencia y valor de la democracia, Comares, Granada, 2002, p. 41. 
son subalternos con respecto a la ciudadanía de mercado y tampoco se puede afirmar que el TC aporte ni un mayor catálogo de derechos políticos, ni una mayor precisión en su contenido y titularidad ${ }^{58}$. Por otro lado, la construcción constitucional europea, de tipo pluralista, obliga a reconocer una doble vía de legitimación, los Estados y los ciudadanos, que se plasma en un sistema institucional donde cada actor guarda una visión particular y a veces divergente sobre la naturaleza y el fin de la integración europea, lo que sin duda tiene incidencia en la formación de la ley comunitaria ${ }^{59}$. Estas limitaciones no hacen sin embargo desaparecer el carácter normativo y valorativo que retiene el principio representativo en el art. I-46 TC, ni pueden plantear dudas en torno al verdadero deber ser del debate constitucional puesto en marcha recientemente, en cuanto a la tarea fundamental que se le tiene que reservar a la representación política: la creación de un auténtico espacio político europeo, más allá de la lógica reguladora del mercado y del consenso intergubernamental permanente entre los Estados miem$\operatorname{bros}^{60}$.

Resulta obligado entonces, preguntarnos si la democracia participativa forjada en los círculos teóricos y políticos de la nueva gobernanza europea, del MAC, y finalmente plasmada en el art. I-47 TC, puede ayudar a la concreción de un espacio político europeo. En nuestra opinión, la respuesta solo puede ser negativa. Limitar los sujetos del principio participativo, como lo hace el art. I-47 TC, a corporaciones, asociaciones representativas y grupos de presión, que únicamente se movilizan desde sus inquietudes e intereses inmediatos, anula el momento deliberativo de la democracia representativa y reduce la expresión de la sociedad europea a lo contingente de sus preocupaciones particulares. De nada sirve apelar a una ficticia e indefinida sociedad civil europea, donde confluye la perspectiva nacional y supranacional, y donde se confunden las organizaciones no gubernamentales con el poder empresarial privado, como esfera de intermediación de la acción

58 Everson, M.: "The Legacy of the Market Citizen», en SHAW, J., y GILIAN, M. (eds.): New Legal Dynamics of the European Union, Clarendon Press, Oxford, 1995, pp. 73-89, y MENÉNDEZ, A. J.: «Esperando a la Constitución Europea», op. cit., p. 100.

59 CAnnizzaro, E.: "La Costituzione pluralista. A proposito della natura giuridica del Tratato costituzionale", I/ Diritto dell'Unione Europea, n. ${ }^{\circ}$ 1, 2005, pp. 1-20, y ToRCHIA, L.: "Una Costituzione senza Stato», en Diritto Pubblico, n. 2 2, 2001.

60 De la misma opinión, MAGneTtE, P.: «European Governance and Civic Participation: Can the European Union be politicised", Jean Monnet Working Papers, n. ${ }^{\circ}$ 6/01, http://www.jeanmonnetprogram.org/papers/, y CLOSA, C.: «El libro blanco sobre la gobernanza", Revista de Estudios Políticos, n. ${ }^{\circ} 119,2003$, pp.501-503. 
social y política ${ }^{61}$. Todo ello porque como ha señalado el profesor Agapito Maestre, "La sociedad civil únicamente aparece, cuando los derechos de libertad política y los derechos de comunicación política están anclados en la conciencia pública de todos y cada uno de los ciudadanos o, mejor dicho, cuando todos y cada uno de esos derechos están asumidos por el ciudadano de tal forma, que la articulación de la diversidad real de las diferentes concepciones del mundo, intereses y opiniones están perfectamente garantizadas" ${ }^{62}$.

Desde esta perspectiva, estamos en condiciones de comprender más claramente cuál es la razón por la que la tesis de la democracia participativa europea, ha surgido en los círculos intelectuales que abogan por la institucionalización de formas blandas y flexibles de gobierno, como es el caso del $\mathrm{MAC}^{63}$. La mera representación y proyección de intereses particulares en detrimento de la voluntad general, como pretende la práctica participativa, tiene como objetivo no declarado la pacificación de las relaciones sociales y económicas existentes, la defensa del status quo constitucional y la negación del antagonismo que le es propio a la verdadera política democrática ${ }^{64}$. Ello en un contexto político neoliberal que propugna una relación de intereses sin la hegemonía del proyecto social que caracterizaba al Estado del bienestar. Así las cosas, no puede parecer extraño que la democracia participativa se configure, a nuestro entender, como el paradigma teórico ideal para legitimar la des-juridificación que el MAC propone para la nueva Constitución económica de la UE, que como hemos señalado con anterioridad, emerge como un poder no vinculante que ejerce su dominio en los diferentes niveles de gobierno sin ser constreñido por las normas que gobiernan la atribución de competencias, la responsabilidad democrática y su control jurídico.

61 Una crítica de la visión de la Comisión Europea en torno a la sociedad civil, en Armstrong, K. A.: «Rediscovering Civil Society: The European Union and the White Paper on Governance", European Law Journal, VI, 8, n. ${ }^{\circ} 1$, 2002, pp. 102-132, y SmISMANS, S.: "European Civil Society: Shaped by Discourses and Institutional Interest", European Law Journal, VI, 9, n. ${ }^{\circ} 4$, 2003, pp. 473-495.

62 Maestre, A.: «Estudio preliminar», en RöDel, U.; Frankenberg, G., y Dubiel, H.: La cuestión democrática, Huega \& Fierro, Murcia, 1997, pp. 19 y 20.

63 HARLOW, C.: "Deconstructing Government?", Yearbook of European Law, Clarendon Press, Oxford, 2005, pp. 57-61.

64 Como ha señalado el profesor VEGA GARcía, P. de: "Legitimidad y representación en la crisis de la democracia actual", Institut de Ciències Polítiques $i$ Socials Working Papers, n. ${ }^{\circ}$ 141, Barcelona, 1998, p. 42. 


\section{CONCLUSIONES}

El objetivo del presente trabajo ha sido poner de manifiesto las transformaciones constitucionales que en la actualidad sufre la Unión Europea, bajo el régimen del experimentalismo democrático que propone la gobernanza liberal. Para ello hemos tomado como referencia el desarrollo teórico e institucional del Método Abierto de Coordinación, nueva forma de gobierno blando y flexible que se aplica al ámbito de la política económica comunitaria ${ }^{65}$. El Método Abierto de Coordinación, auténtica expresión de la gobernanza para-constitucional europea, propone que la diversidad económica estructural de los Estados miembros, sea integrada en la nueva Constitución económica a través de formas débiles de gobierno, donde prime la cooperación sobre la integración y la persuasión política sobre la coerción jurídica. Este modelo gubernamental, fundado en la abierta irresponsabilidad política de quienes toman (o no toman) las decisiones, donde el proceso político permanece ajeno a la dinámica parlamentaria, recurre en su búsqueda de legitimidad a fórmulas democráticas participativas y a prácticas administrativas del buen gobierno, búsqueda que se ha visto reflejada en la redacción del Título VI del TC, "de la vida democrática de la Unión».

Sin embargo, como hemos tenido la oportunidad de comprobar, la democracia representativa y la democracia participativa, nos remiten a dos concepciones antagónicas de cómo construir un hipotético espacio político europeo ${ }^{66}$. En el contexto de la dimensión histórica del constitucionalismo, el principio representativo aparece como un elemento fundamental por varias razones: resuelve la tensión dialéctica entre el poder constituyente y los poderes constituidos, asegura la autonomía del proceso político frente a otros aspectos que se desarroIlan dentro del sistema social y dota de legitimidad al ejercicio del poder público, al vincular la responsabilidad democrática con la temporalidad y la rotación de los cargos desde donde se ejerce ese

65 El término aparece en un sentido distinto, en LINDSETH, P. L.: « «Weak» constitutionalism? Reflections on Comitology and Transnacional Governance in the European Union", Oxford Journal of Legal Studies, VI, 21, n. ${ }^{\circ} 1,2001$, pp. 145 y ss.

66 El TC también introduce otros antagonismos de tipo constitucional: el profesor Carlos Closa distingue a este respecto la Constitución como límite y la Constitución como programa; ver ClosA MonTERO, C.: "Constitución y democracia en la Unión Europea", en Closa Montero, C., y Fernández Sola, N. (coords.): La Constitución de la Unión Europea, Centro de Estudios Políticos y Constitucionales, Madrid, 2005, pp. 17-39. 
mismo poder ${ }^{67}$. Sin embargo, cuando se invoca la democracia participativa, como método constitucional apropiado para tomar decisiones, o al menos para influir en ellas, como se hace en el art. I-47 TC, es necesario advertir que se está dando cuerpo a una forma distinta de legitimidad política. Todo ello porque se apela a un consenso y un diálogo silencioso y corporativista, donde el ciudadano, sujeto de derechos políticos, y los partidos políticos, organizaciones que expresan el pluralismo político, que concurren a la formación y manifestación de la voluntad popular, y que se configuran como instrumentos fundamentales de la participación política, son desalojados del ágora pública por entidades y organizaciones colectivas que sólo pueden asumir los intereses parciales de a quienes representan ${ }^{68}$.

En este sentido, sólo nos cabe decir que los problemas constitucionales y democráticos por los que atraviesa la Unión, no pueden ser solventados recurriendo a una democracia de trueque, de toma y daca, donde la apelación al principio participativo para justificar las prácticas corporativas, como hace el art. I-47 TC, no es en rigor más que una fórmula política vacía destinada a encubrir la participación de los privilegiados. Por el contrario, el dilema democrático de la Unión comenzará a superarse cuando el ciudadano europeo tome conciencia de que la ley es fruto de su propia voluntad, es decir, cuando el constitucionalismo comunitario adquiera un significado verdaderamente político y sea capaz de movilizar el interés general de la sociedad política europea en su conjunto ${ }^{69}$.

${ }^{67}$ Resulta difícil encontrar, dentro de la filosofía política, un autor donde se reflejen con mayor claridad las virtudes del poder democrático a través del principio de la representación, como en LEFORT, C.: La incertidumbre democrática. Ensayos sobre lo político, Anthropos, Barcelona, Barcelona, 2004, pp. 23-35.

68 Nótese que cuando definíamos la función de los partidos políticos, lo hacíamos en términos parecidos a como lo hace el art. 6 de la Constitución Española y el art. 21 de la Ley Fundamental de Bonn.

69 Existen, en este sentido, pocos autores que reclamen la vuelta a Rousseau, como en realidad nosotros hacemos al final de nuestro trabajo, para democratizar el constitucionalismo de la Unión Europea. En el ámbito específico de la doctrina española, ver RUIPÉREZ, J.: La Constitución europea y la teoría del Poder Constituyente, Biblioteca Nueva, Madrid, 2000, en especial el último capítulo; en el contexto europeo, recomendamos ver ALLOTT, P.: "European governance and the re-branding of democracy", European Law Review, n. ${ }^{\circ} 27,2002$, en especial pp. 70 y 71. 